\title{
What Is In Your Workplace Toolbox? Recognizing And Developing Spiritual Intelligence Through Problem Solving
}

Author 1, ORCID: https://orcid.org/0000-0002-1622-9796

Author 1 Affiliation: Janelle C. Hall, PhD, Walden University, Minneapolis, MN

SC Classification Genre: Business

Creative Commons Attribution

Citation: Hall, J. C. (2021) What is in your workplace toolbox? Recognizing and developing spiritual intelligence through problem solving. Scholar Chatter, 2(3), 1- 13. http://doi.org/10.47036/SC.2.3.1-13.2021

(C) The Author. 2021. This is an open access publication through Scholar Chatter Society of Academic Publishers.

\begin{abstract}
Performance management frameworks in public educational institutions have not dealt with some of the challenges in creating an environment that reflects organizational commitment, sustainability, productivity, and retention among academic staff. The purpose of this article was to explore the experiences of people of color regarding the challenges they face involving the use of spiritual intelligence in the workplace. Gardner's multiple intelligence theory served as the foundation for this article. The key research question focused on the perceptions of people of color working in nonprofit educational institutions regarding the role that spiritual intelligence played in their workplaces and career successes. Targeted research included face-to-face interviews with 10 participants older than 18 years old. Two findings revealed spiritual intelligence was viewed as an indirect tool used for career success and there are opportunities for human resources to promote spiritual intelligence to create a sustainable work environment to increase performance. I concluded that the results are useful for human resource management to implement programs for their employees to understand and apply their spiritual intelligence in the workplace environment.
\end{abstract}

Keywords: People of Color, Organizational Culture, Spiritual Intelligence, Organizational Commitment, Human Resource Development

\section{Introduction}

Organizations have dissatisfied and unmotivated employees, causing the organizations to suffer. Human resource management and public policy fail to address how exposure to spiritual intelligence in the workplace can create an organization where employees feel they can perform to their full potential. This study examined the influence of spiritual intelligence on career success with people of color, the work outcomes of spiritual intelligence, and how spiritual 
intelligence leads to career success. This study focused on the spiritual intelligence and career success among people of color working in nonprofit educational institutions, and it enhances prior research on the influence of spiritual intelligence in the workplace. This research addresses a gap in knowledge by focusing on spiritual intelligence among people of color in educational organizations.

Human resources and managers need to spend time on keeping their employees satisfied. Employees make up organizations, and if the employees do not have the organization's commitment and incentives to excel, their existence will not extend within the organization. Researchers argued that spirituality and religion in the workplace receive attention for several reasons starting with distrust in the workplace, unhappiness, connection, and individuality (Benefiel et al., 2014).

\section{Research Question}

What are the perceptions of people of color working in nonprofits educational institutions as it relates to the role spiritual intelligence plays in the workplace and career success?

\section{Literature Review}

\section{Spiritual Intelligence}

Spiritual intelligence can be a way of using and controlling emotions in a positive way. As a pssible enhancement to workplace productivity, spiritual intelligence has gained the interest of scholars and practitioners (Mamman \& Zakaria, 2016; Munawar \& Tariq, 2017). We need to have an understanding that of all types of intelligence, human intelligence (IQ) is the root of the history of life. It is the kind of intelligence that enables us to do rational, logical, and rule-bound thinking, emotional intelligence (EQ) allows us to do our associative, habit-bound, patternrecognizing, and emotive thinking. The third kind of intelligence allows us to address and solve problems. This happens by being insightful, adhering to rule making, and avoiding rule-breaking thinking. This also is seen as the intelligence with which we reframe and transform our previous thinking this gives us spiritual intelligence (Zohar \& Marshall, 2000). Spiritual intelligence is the necessary foundation for the effective functioning of both human intelligence and emotional intelligence (Zohar \& Marshall, 2000).

Gardner argued that multiple intelligences help people understand that intelligence is more than one property of the human mind. The nine types of intelligences include (a) natural, (b) linguistic, (c) musical, (d) physical, (e) emotional, (f) logical, (g) interpersonal, (h) existential, and (i) spatial (Gardner, 1999). Gardner's theory of multiple intelligences did not include spiritual intelligence but instead used existential intelligence (1999). Gardner later believed existential intelligence gives one the ability to reason with deep existential questions of life and meaning (2000). Amoako argued that spiritual intelligence is hard to measure because it is based on an individual's way of dealing with life and how one makes sense of everything (2019). 
Organizational culture consists of shared values and beliefs that guide a person to adopt specific behavior (Amoako, 2019). Organizational culture is also defined as a collection of expectations, values, and practices that assist the actions of members of an organization (Amoako, 2019). Organizational culture can play a vital role in performance when established properly. A growing number of companies such as the fast-food chain Chick-Fil-A are using spiritual lessons in their management and leadership strategies (Conlin, 1999; Fry \& Slocum, 2008; Samul, 2019). Incorporating those lessons has been referred to as a spiritual awakening in the American workplace (Garcia-Zamor, 2003). Chick-Fil-A's operation is consistent with the literature on spiritual intelligence at work that can be beneficial to the organization. Chick-Fil-A continues to rank in customer service, employee satisfaction, profits, job security, and performance then others in the industry (Hacker \& Washington, 2017).

\section{Spiritual Intelligence and Organization Commitment}

Spiritual intelligence can be effective in the promotion of different variables such as individual preferences, diversity, and effective work performance. The best performance and the greatest happiness of workers occur when they believe in what they are doing and when they feel committed rather than compelled in doing the activity (Giacalone \& Jurkiewicz, 2010). Organizational commitment is an individual's identification and involvement with a particular organization. It is defined by a belief in and acceptance of the organization's goal and values, a willingness to exert effort on behalf of the organization, and a desire to maintain membership in the organization Dirgahayu, 2020). One such variable is organizational commitment which may have potentially serious effects on an organization's function and can be a significant influence on its effectiveness (Kalantarkousheh et al., 2014).

The positive effects of spiritual intelligence in the promotion of an organization's effectiveness and the individual growth of employees require consideration. A meaningful relationship has been shown to exist between spiritual intelligence and organizational commitment of an organization's employees. When an individual's spiritual intelligence increases, the organizational commitment also increases (Kalantarkousheh et al., 2014). Organizational commitment is an important means of workers' job satisfaction (Ayranci \& Ayranci, 2017). Organizational commitment is a valuable reaction toward the entire organization (Andreana \& Putri, 2020). In fact, the promotion of spiritual values in the organization certainly enhances employee's organizational commitment, performance, morality, and job satisfaction (Brophy, 2014; Van der Walt \& de Klerk, 2014).

\section{Job Satisfaction}

Spiritual intelligence enables people to live with greater meaning and depth and to look for a meaning beyond the physical needs and a low-level life in their business. Spiritual intelligence will also assist the workers in achieving their happiness and satisfaction with their current jobs. Eventually, spiritual intelligence will help the organizations to achieve business objectives and allow the employees to flourish within the organization (Tehubijuluw, 2014). Most experts are of the same belief that job satisfaction is associated with mental and social factors. If a job secures the individual with the desired joy, then they will be satisfied with their job. Job satisfaction is one of the significant factors in job success. Spirituality in the workplace 
can increase job satisfaction and workers' productivity (Hassan et al., 2016). It is a factor that causes efficiency and personal satisfaction (Tabancali, 2016).

\section{Spiritual Intelligence and Human Resources Development}

Human resource development is a set of formal organizational and individual practices designed to enhance the potential contribution of human resources to the organization (Walton, 1999). The field of human resource development developed into the field of human resource management (McGoldrick et al., 2003). Both professions share similar backgrounds in psychology in the organizations (Hassan et al., 2016). Human resource development is a field of study and practice that will ensure sustainable innovation via the continuous and efficient utilization of resources, creative and dedicated people, technology, structure, and conducive working culture which will lead to greater organizational performance and productivity (Watkins \& Marsick, 2014). Development initiatives were discovered reflecting a growing approach to human resource development (Stokes et al., 2016).

A trend among organizations is failing to have a holistic approach to human resource development. A model of employee behavior and identified the basic factors that shape individual behavior in internal and environmental forces (Werner \& Desimone, 2011). Their model depicts employee-related forces such as motivation, attitudes, knowledge, skills, abilities. Likewise, environmental factors are supervisors, the organization, and colleagues. Spiritual organizations encourage creative thinking and cooperation of organizational units to establish and accomplish mutually agreed-upon mission statements and objectives for the organization.

Spiritual organizations are likely to have a greater openness to change. Their belief in abundant resources leads to greater interconnectedness and cooperation between organization units and empowerment of workers at all levels of the organizations (Brophy, 2014). These organizations can be more concerned with existing in harmony with their environment rather than believing in the preservation of self at all costs, there are three reasons organizations should want staff to incorporate their spiritual values (Brophy, 2014):

(a) The character of a business should represent, rather than defy, or distort, the deeply held values of its constituent; (b) a collective activity, such as a business, that alienates constituents from their deeply held values is morally objectionable, especially if these values can be practically incorporated into the activity without violating the freedom or consent of any of the constituents; and (c) it enhances, rather than running counter to, the freedom and consent of its participants (provides that these values are shared). (p. 779)

\section{Methodology}

The research population comprised people of color working in nonprofit educational institutions based in New Jersey. Education Database, an organizational resource guide, is the world's largest source of information on nonprofit organizations. There were 327 private nonprofit educational institutions in this area. Individual employees working in nonprofit educational institutions were asked to participate in the study by invitation (OECD,2021). The sampling population was identified by me using the GuideStar database listing and people of 
various income demographics. Thirty participants were a person of color, ages 18 years and older, and employed for at least one calendar year.

\section{Findings}

Research questions embed the values, world views, and direction of an inquiry and were influential in determining what type of knowledge the interview process generated. As stated earlier in the study, the research question that guided the study was: What are the perceptions of people of color working in nonprofits educational institutions as it relates to the role spiritual intelligence plays in the workplace and career success?

The following interview questions helped me collect data regarding how spiritual intelligence contributes to career success among people of color working in nonprofit educational institutions and reveal the answer to the research question:

- Tell me about a time you faced a dilemma at work. How did you deal with it and what was the result?

- How would you resolve a dispute between two colleagues?

- What type of working environment brings out your best performance? Your worst?

- When have you felt demotivated and what did you do to overcome this?

- Have you ever had to change your behavior at work, if so, why did you have to change and how did you change?

- How do you respond when a co-worker challenges you?

- Have you ever had to change your behavior at work, if so, why did you have to change and how did you change?

The interviews began with open-ended questions about the participants, followed by more probing questions, and concluded with open-ended questions framed to gather more data on career success and spiritual intelligence. The interviews took place in person in a single session. Data were read several times to decipher content and intent. Coding of transcripts happened in the order of the interviews. The coding process allowed me to reflect as theories began to emerge. Coding utilized qualitative data analysis computer software. The data analysis process included a preliminary coding framework (Table 1).

Table 1. Precoding Analysis

\begin{tabular}{lc}
\hline Spiritual Intelligence & Code \\
\hline Regulate one's behavior & SQROB \\
Morals/ ethics/ values & SQMEV \\
Relationships & SQR \\
Strive & SQS \\
Emotions & SQE \\
Interpersonal & SQI \\
Problem solving & SQPS \\
\hline
\end{tabular}

During the coding process, data were reviewed from the previous interviews to ensure their connections were made and noted if saturation occurred. Constant comparison is the 
process of analyzing and comparing new data to existing data. Coding terminology used for this study came from two cycles of coding as first- and second-cycle coding methods (Saldana, 2016). First-cycle coding is the initial way of summarizing segments of data. First-cycle methods are those processes that happen during the initial coding of data which are divided into seven subcategories that include (a) grammatical, (b) elemental, (c) affective, (d) literary Language, (e) exploratory, (f) procedural, and (g) theming the data. Each subcategory has significant characteristics. Most first-cycle methods are relatively direct. First-cycle codes and their associated coded data are reorganized and reconfigured to eventually develop a smaller and more select list of broader categories, themes, concepts, and/or assertions (Saldana, 2016).

The intent of this qualitative study was to explore spiritual intelligence and career success among people of color working in nonprofit educational institutions. Data analysis began with attempting to understand core themes and develop association between data. The data analysis process included a preliminary coding framework linking the interview protocol with the theoretical framework and research question. The research question harmonized with ontological, epistemological, and other stances with the study (Trede \& Higgs, 2009). The preliminary coding framework linked the interview protocol with the theoretical framework and research question; allowing a focus on the theory to align the data collection protocol with the data analysis. Accomplishing the preliminary classification for data organization involved entering the data into NVivo12 and then organizing it by using Microsoft Word. The concluding stage of analysis emphasized combined experiences of individuals and provided insight into spiritual intelligence and career success. Data were compiled and organized for consistency; seven themes were relevant to the research questions developed from the data (Table 2).

Table 2. Summary of Themes

\begin{tabular}{lc}
\hline Themes & Aggregate Coding Frequency $(f)$ \\
\hline Morals & 107 \\
Regulate one's behavior & 69 \\
Relationship/interpersonal & 61 \\
Ethical/strive & 39 \\
Values & 37 \\
Problem solving & 25 \\
Emotions & 16 \\
\hline
\end{tabular}

The query matrix (Appendix B) represents the themes and individual codes. After reviewing each participants' response, a link was formed to a theme and code. The query matrix consists of rows and columns of themes and codes. The table cells were color coded to quickly identify where the most coding occurred. The columns contained the themes such as morals, values, and relationships. The rows contain the codes such as know, team, change, well, and environment. The cells displayed the frequency of codes referenced in each theme at the intersection of a row and column. Any codes with a frequency of less than 10 were not included in the thematic analysis. 


\section{Identification of Themes}

At the core of qualitative data analysis is the task of discovering themes. Themes are facets of research participants' accounts characterizing perceptions and/or experiences that I found relevant to the research question. Themes included information from analyzing the characteristics associated with research questions. Research participants' experiences and perceptions were taken from direct quotes from responses to each interview.

\section{Theme 1: Morals $(f=107)$}

The following interview questions addressed the theme of morals: How would you resolve a dispute between two colleagues and tell me about a time you faced a dilemma at work; How did you deal with it and what was the result? The theme morals refer to one's own principles regarding right and wrong. It is the intelligence that makes people whole, which allows them to integrate the many fragments of their lives, activities, and being. Participants interviewed employed their spiritual intelligence when understanding how to accept disruptions in moral personal patterns. Participants discussed social dynamics that helped shape them into who they are today. Many of the participants interviewed cited a sense of balance, ability to remind themselves to keep a positive disposition, and complete any task because of their spiritual intelligence. The codes included with this theme were know $(f=31)$, right $(f=10)$, feel $(f=12)$, understand $(f=10)$, and listen $(f=16)$. Participants were asked about the type of work environment they felt allowed them to bring out the best and worst in their performance.

\section{Theme 2: Regulate Ones' Behavior $(f=69)$}

The following interview questions addressed the theme of regulate one's behavior: How do you respond when a co-worker challenges you and have you ever had a change your behavior at work, if so, why did you have to change and how did you change? The common thread of this theme is that participants exhibited a preference to contemplative thought and reflection about the impact of regulating one's behavior when choosing to reflect and taking a step-back. Participants expressed facing personal challenges while navigating through their career. Spiritual intelligence engages in virtuous behavior by showing forgiveness and displaying compassion and wisdom. Spiritual intelligence is the ability of individuals to behave with wisdom and compassion while maintaining inner and outer peace, regardless of the situation (Wigglesworth, 2012). The codes most frequently associated with this theme were know $(f=45)$, think $(f=20)$, professional $(f=15)$, and recognize $(f=10)$. When asked whether they have ever had to change their behavior at work and how and why this change occurred, participants responded by providing their experiences concerning the impact of their behavior in the workplace.

\section{Theme 3: Relationship/Interpersonal $(f=61)$}

The following interview question that relates to this theme is: What type of working environment brings out your best performance? Your worst? The theme of relationship/interpersonal was communication among the participants. The codes included with this theme were know $(f=18)$, think $(f=10)$, well $(f=8)$, conversation $(f=7)$, respond $(f=6)$, and support $(f=4)$. The workplace constitutes people. With people, there is a need for relationships. Employees with good interpersonal skills should be seen as an asset in the 
workplace. Spiritual intelligence increases an individual's capacity to understand others at a higher level. Spiritual intelligence understanding allows an individual to discern both the 'true cause' of behavior without judgment and serve the 'true needs' of others. Spiritual intelligence increases workplace relationships and the individual's capacity to understand others at a higher level. Spiritual intelligence also aids in the development of a stable sense of identity among individuals especially in the context of workplace relationships.

\section{Theme 4: Ethical/Strive $(f=39)$}

The interview question asking participants, When have you felt demotivated and what did you do to overcome that feeling? addressed the theme of ethical/strive, that involves when one refers to rules from an external source and makes great efforts to achieve or obtain something. Codes most frequently occurring in the data representing this theme were known $(f=6)$, think $(f=5)$, well $(f=8)$, facts $(f=4)$, and motivated $(f=8)$. Ethics promotes teamwork among colleagues and builds confidence and honesty. The ethical values are based on justice, honesty, and human virtues. These are logical and ethical principles which employees are required to observe (Esfahani \& Najafi, 2015). Ethical issues typically occur because of conflicts between an employee's personal and moral beliefs and values and the core values of the organization's internal environment. Conflict starts when an employee attempts to fulfill their own goals instead of organizational goals (Esfahani \& Najafi, 2015). Participants were asked about how they would respond when a co-worker challenges them. This question permitted research participants to provide their experiences concerning how employees incorporate problem solving and effective communication skills to restore workplace relationships.

\section{Theme 5: Values $(f=37)$}

The following interview questions addressed the theme of value: How do you respond when a co-worker challenges you, how would you resolve a dispute between two colleagues, and tell me about a time you faced a dilemma at work. How did you deal with it and what was the end result? The theme of value focused on when ones believe things that are important in the way they live and work. The codes included with this theme were know $(f=26)$, think $(f=7)$, well $(f=8)$, right $(f=6)$, and feel $(f=7)$. Zohar and Marshall (2000) indicated that people look for meaning and value in what they do as people are driven by questions about why we exist and what is the meaning of our lives. People have a longing to feel a part of the larger reason, something in the direction of which people can aspire. Spiritual intelligence helps employees with aligning personal values with a clear sense of purpose that demonstrates their integrity level high in the organization (Chin et al., 2011). Spiritual intelligence is the ultimate intelligence which allows people to see the larger context in which actions take place, and it gives to the lives of individuals an overarching canopy of meaning and value (Zohar \& Marshall, 2000). Participants were asked about when they felt demotivated and what they did to overcome it.

\section{Theme 6: Problem Solving $(f=25)$}

The following interview question was asked to address the theme of problem solving: Have you ever had to change your work behavior at work, if so, why did you have to change and how did you change? The theme of problem solving encompassed the process of finding solutions to difficult or complex issues. The codes included with this theme were know $(f=12)$, 
listen $(f=12)$, think $(f=10)$, solution $(f=10)$, and right $(f=8)$. SQ is the ultimate intelligence which people use to address and solve the problems associated with meaning and value. It is the intelligence that has the force to help people use their actions and lives in a wider, richer, and meaning-giving context. Spiritual intelligence enables them to solve these problems and find peace about them. Spiritual intelligence as the adaptive use of spiritual information to facilitate everyday problem solving and goal attainment (Emmons, 2000). Spiritual intelligence gives people potential to assess and understand that one course of action or one way of life is more meaningful than the other (Hacker \& Washington, 2017). Participants were asked about a time they faced a dilemma at work: Tell me about a time you faced a dilemma at work. How did you deal with it and what was the result? This question permitted research participants to share their experiences regarding their critical thinking skills. Understanding critical thinking skills is used to evaluate a situation and/or issue. Critical thinking helps one make decisions that can be used to help cope with everyday problems. The use of critical thinking skills is a challenge in the $21^{\text {st }}$ century organization. Organizations identify the need for critical thinking to impact the success of the employees and organizations. Executive administrators realize that employees with critical thinking skills can use the information to see all aspects of a situation and are able to make outstanding decisions (Reed \& Burrell, 2019).

\section{Theme 7: Emotions $(f=16)$}

The following interview question: When have you felt demotivated and what did you do to overcome this? focused on the theme of emotion that involved an intuitive feeling as distinguished from reasoning or knowledge. The codes included with this theme were know $(f=9)$, think $(f=8)$, well $(f=8)$, conversation $(f=7)$, listen $(f=4)$, and moment $(f=2)$. Spiritual intelligence can play an important role in making more efficient cognitive emotion regulation strategies, and the students with stronger spiritual intelligence were able to regulate their emotions more effectively.

\section{Discussion}

Each theme culminated in answering the research question: What are the perceptions of people of color working in nonprofit educational institutions as it relates to the role spiritual intelligence plays in the workplace and career success? I confirm that these themes culminated into answering the research question in full, including supporting theories. Gardner's theory of multiple intelligences proposed that individuals have multiple intelligences rather than a general intelligence that underlies performance in all tasks; however, the theory did not include spiritual intelligence instead used existential intelligence (Gardner, 1999). Gardner later believed existential intelligence gives one the ability to reason with deep existential questions of life and meaning (2000). Although each participant may not have a clear understanding of spiritual intelligence, many of them recognized and understood that their personal discernment helped them better control their inner thoughts that create observable behavior and played an important part in their career success. Based on research findings from the previous literature review and research participants, it is important for organizations to develop strategies to ensure employees are not only introduced to spiritual intelligence but have a comprehensive understanding of the concept. Additionally, it may be important for organizations to create comprehensive strategies to address diverse aspects of spiritual intelligence such as spending time to reflect on their 
purpose of life, gaining familiarity with spiritual intelligence, and making a commitment to spiritual intelligence.

\section{Funding}

The author received no financial support for the research, authorship, and/or publication of this article.

\section{Acknowledgements}

I would like to thank Dr. Julie Conzelmann for her support and guidance during this process. I would also share gratitude to the Scholar Chatter Society of Academic Publishers for providing a space for me to continue my scholarly research endeavors.

\section{References}

Amoako, G. K. (2019). A conceptual framework: Corporate environmental management activities and sustainable competitive advantage. Management of Environmental Quality: An International Journal. https://doi.org/10.1108/meq-09-2019-0187

Andreana, M., \& Putri, I. (2020). The effect of intellectual intelligence, emotional intelligence, spiritual intelligence and gender on ethical behavior. Accounting, 6(7), 1411-1418. https://doi.org/10.5267/j.ac.2020.8.008

Ayranci, A., \& Ayranci, E. (2017). Relationships among perceived transformation leadership, workers' creativity, job satisfaction, and organizational commitment: An investigation of Turkish banks. International Journal of Academic Research in Business and Social Sciences, 7(4), 3-22. https://doi.org/10.6007/ijarbss/v7-i4/2823

Benefiel, M., Fry, L. W., \& Geigle, D. (2014). Spirituality and religion in the workplace: History, theory, and research. Psychology of Religion and Spirituality, 6(3), 175-187. https://doi.org/10.1037/a0036597

Brophy, M. (2014). Spirituality incorporated: Including convergent spiritual values in business. Journal of Business Ethics, 12(3), 1-16. https://doi.org/10.1007/s10551-014-2337-y

Chin, S. T. S., Anantharaman, R. N., \& Tong, D. Y. K. (2011). The roles of emotional intelligence and spiritual intelligence at the workplace. Journal of Human Resources Management Research, 2011, 1-9. https://doi:10.5171/2011.582992

Conlin, M. (1999). Religion in the workplace: The growing presence of spirituality in corporate America. In R. A. Giacalone \& C. L. Jurkiewicz, Handbook of workplace spirituality and organizational performance, pp. 150-154, 156, 158. Jossey-Bass. https://doi.org/10.4324/9781315703817 
Dirgahayu, P. P. (2020). The influence of organizational commitment, quality of work life (QWL) on organizational citizenship behavior (OCB) and employees performance. Journal of Advanced Research in Dynamical and Control Systems, 12(01-Special Issue), 812-824. https://doi.org/10.5373/jardcs/v12sp1/20201133

Emmons, R. A. (2000). Is spirituality an intelligence? The International Journal for the Psychology of Religion, 10(1), 1-26. https://doi.org/10.1207/S15327582IJPR1001_2

Esfahani, S. T., \& Najafi, A. (2015). The relationship between spiritual intelligence and professional ethics. WALIA Journal, 31(S3), 179-186. http://waliaj.com/wpcontent/2015/Special\%20Issue\%203,\%202015/35\%202015-31-S3-pp.179-186.pdf

Fry, L. W., \& Slocum, J. W. (2008). Maximizing the triple bottom line through spiritual leadership. Organizational Dynamics, 37(1), 86-96. https://doi.org/10.1016/j.orgdyn.2007.11.004

Garcia-Zamor, J.-C. (2003). Workplace spirituality and organizational performance. Public Administration Review, 63(3), 355-363. https://doi.org/10.1111/1540-6210.00295

Gardner, H. (1999). Intelligence reframed: Multiple intelligences for the $21^{\text {st }}$ century. Basic Books.

Gardner, H. (2000). A case against spiritual intelligence. The International Journal for the Psychology of Religion, 10(1), 27-34. https://doi.org/10.1111/1540-6210.00295

Giacalone, R., \& Jurkiewicz, C. L. (2010). Spiritual well-being, spiritual intelligence, and healthy workplace policy. In Emmons, R., Keortge, S., \& Paloutzian., R. (Eds.), Handbook of workplace spirituality and organizational performance (pp. 73-86). https://doi.org/10.4324/9781315703817

Hacker, S. K., \& Washington, M. (2017). Spiritual intelligence: going beyond IQ and EQ to develop resilient leaders. Global Business and Organizational Excellence, 36(3), 21-28. https://doi.org/10.1002/joe.21777

Hassan, M., Bin Nadeem, A., \& Akhter, A. (2016). Impact of workplace spirituality on job satisfaction: Mediating effect of trust. Cogent Business \& Management, 3(1). https://doi.org/10.1080/23311975.2016.1189808

Kalantarkousheh, S. M., Sharghi, N., Soleimani, M., \& Ramezani, S. (2014). The role of spiritual intelligence on organizational commitment in employees of universities in Tehran Province, Iran. Procedia - Social and Behavioral Sciences, 140, 499-505. https://doi.org/10.1016/j.sbspro.2014.04.460

Mamman, A., \& Zakaria, H. B. (2016). Spirituality and ubuntu as the foundation for building African institutions organizations and leaders. Journal of Management, Spirituality \& Religion, 13(3), 246-265. https://doi.org/10.1080/14766086.2016.1159976 
McGoldrick, J., Stewart, J., \& Watson, S. (2003). Researching HRD: Philosophy, process, and practice: Jim McGoldrick, Jim Stewart, and Sandra Watson. In Understanding Human Resource Development (pp. 20-36). Routledge. https://doi.org/10.4324/9780203361191$\underline{8}$

Munawar, K., \& Tariq, O. (2017). Exploring relationship between spiritual intelligence, religiosity and life satisfaction among elderly Pakistani Muslims. Journal of Religion and Health, 57(3), 781-795. https://doi.org/10.1007/s10943-017-0360-X

OECD (2021), "Education Database: Population data (Edition 2020)", OECD Education Statistics (database). https://doi.org/10.1787/06d1e215-en

Reed, M., \& Burrell, G. (2019). Theory and organization studies: The need for contestation. Organization Studies, 40(1), 39-54. https://doi.org/10.1177/0170840617745923

Saldana, J. (2016). The coding manual for qualitative researchers $\left(3^{\text {rd }}\right.$ ed.). Sage.

Samul, J. (2019). Spiritual leadership: Meaning in the sustainable workplace. Sustainability, 12(1), 267. https://doi.org/10.3390/su12010267

Stokes, P., Baker, C., \& Lichy, J. (2016). The role of embedded individual values, belief, and attitudes and spiritual capital in shaping everyday postsecular organizational culture. European Management Review, 13(1), 37-51. https://doi.org/10.1111/emre.12065

Tabancali, E. (2016). The Relationship between Teachers' Job Satisfaction and Loneliness at the Workplace. Eurasian Journal of Educational Research, 16(66), 1-30. https://doi.org/10.14689/ejer.2016.66.15

Tehubijuluw, F. K. (2014). The effect of spiritual intelligence to increase organization performance through workers' job satisfaction. Business and Entrepreneurial Review, 14(1), 1-14 https://doi.org/10.25105/ber.v14i1.49

Trede, F., \& Higgs, J. (2009). Framing research questions and writing philosophically: The role of framing research questions. In Writing qualitative research on practice (pp. 13-25). Brill Sense. https://doi.org/10.1163/9789087909086_003

Van der Walt, F., \& de Klerk, J. J. (2014). Workplace spirituality and job satisfaction. International Review of Psychiatry, 26(3), 379-389. https://doi.org/10.3109/09540261.2014.908826

Walton, J. (1999). Strategic human resource development. Financial Times.

Watkins, K. E., \& Marsick, V. J. (2014). Adult education \& human resource development: Overlapping and disparate fields. New Horizons in Adult Education and Human Resource Development, 26(1), 42-54. https://doi.org/10.1002/nha3.20052

Werner, J. M., \& Desimone, R. L. (2011). Human resource development. Cengage Learning. 
Wigglesworth, C. (2012). SQ21: The 21 skills of spiritual intelligence. Selected Books.

Zohar, D., \& Marshall, I. (2000). SQ: Connecting with our spiritual intelligence. Bloomsbury. 